\title{
The Strategic Thinking about Export Popularization of Chinese Martial Arts under the Field of View of Global Value Chain
}

\author{
QiaoYaJun
}

\author{
Zhengzhou shengda college of economic and trade Zhengzhou 451191
}

Keywords: martial arts, global value chain, development.

\begin{abstract}
The scientific research of Chinese martial arts is the research of continuation and development in the final analysis. The article proposes the strategic thinking about export popularization of Chinese martial arts under the theory of the view of Global Value Chain; with the usage of research approaches of document-data method and logical-inference, etc; combined with the actual development of Chinese martial arts. According to the article, in the new era of globalization, there is a need of rational thinking for globalization. According to the export popularization of Chinese Martial Arts, as well as the promotion of goods, there is not only a need of far-sight development ideal, but also a need to build a scientific strategy chain system of global development. The export popularization of Chinese martial arts is a comprehensive cultural project. Its effective promotion should be under the leadership of the conciliation panel of State Council, and takes the lead by the State Physical Culture Administration, cooperate and participate closely by Ministry of Education, Culture, Ministry of Finance and other relevant ministries. It is a national project.
\end{abstract}

\section{Introduction}

Nowadays, in the era of globalization, challenges are overlapping with opportunities. The international competition has been developed into the strategic competition and soft power competition increasingly. With the trend that countries all over the world want to expand their nation's international interests, the phenomenon of inter-cultural exchange, confrontation, and blend are becoming prominent day by day. Especially with the rising status of overseas interest in the national interest structure in many countries, the function of cultural soft power has become more and more important than any period of time. Make a general survey of the process of the rise of China, her path of rising is different from it in western big powers. Known as ceremonies, the Chinese nation took the road of peaceful rising abruptly way by working hard for the prosperity of the country. The role of cultural soft power is its strategic value appearance in the process of development. People all over the world feel deep respect for the Chinese Pattern, Chinese experience and Chinese culture quietly. The tendency of loving, respecting for Chinese culture is booming gradually. The powerful features of the role of cultural soft power are being highlighted.

\section{About the global value chains}

The term of global value chain belongs to theoretical vocabulary in business community. In the year of 1985, Harvard business school Professor Michael Porter presented the theory of value chain in his book entitled Competitive Advantage. He put forward the idea that "each enterprise is a collection, in which the processes of designing, producing, selling and assisting carry out. All these processes can be presented by a value chain". The value of enterprises is created through a series of activities which have different responsibilities respectively. However, these activities also contact with each other and collaborate closely, which forms a dynamic process of creating value. In Competitive Advantage, Michael Porter also breaks through the limits of the enterprise and extends his angle to economic interaction between different enterprises. In this stance, he presents the concept of value system which is the base of global value chain. Thereafter, the theory of global value chain has new development, focusing on "goods or service value and global network organization connected by processes of production, sales, recycling, involving in the processes from the raw material acquisition and transportation, semi-finished products' and finished products' production and distribution to final consumption and recycling of the entire process.” It includes all of the participants, production, sales and other activities of the organization and its distribution of value and profit and so on. 


\section{Driving mechanism of global value chain}

Due to the global value chain is a system built on the basis of global industrial chain the driving forces of the global value chain mainly from two aspects of producers and buyers. On the surface, production and sales is a pair of very common unity, but actually, Humanistic elements are behind simple things, which adhere to the dynamic mechanism of scientific system. Especially in contemporary real life, although the acting rules under each kind of dynamic mechanism are needed and obeyed in industrial upgrading process, the industrial development is a changeable dynamic process. The applicable rules and methods today and may backfire tomorrow. Therefore, the research of any dynamic mechanism in global value chains in the exploration and development, and any kind of dynamic mechanism needs to revise strategy continuously according to the constant change of the world as well as actual situation of people's consuming attitudes. Otherwise, the advantage will be lost and the level will decrease.

The governance of the global value chains

Martial arts came of China, and China is the pioneer who takes on heavy responsibilities of the promotion of martial arts in to the global value chain. In order to make the promotion of martial arts lasting and effective, it is particularly important to establish a stable and effective management organization. Because China occupies the dominant position of the global value chain of martial arts, and plays the role of headquarters. There is a need of unified command and making overall plans and coordinate in the process of talents training, technology promotion, and other related activities of martial arts. The leadership and guiding role of China plays in the value chain can not be lost.

\section{The superiority of Martial Arts inserted into the global value chains}

\section{Cultural Superiority}

Culture is the lever of spirit. Although there are different kinds of schools, and covering different fields, and distinctive technologies of martial arts, in connection with the requirements of the motivation and the purpose of martial arts, we intertwine the learning of martial arts with conducting oneself closely. We put the moral on the commanding position. To sum up the rules and commandments of various schools of martial arts, the benevolence, righteousness, propriety, wisdom, faith, loyalty, courage, etc are all the smriti contents that they stressed. The classic spirit and traditional virtues in the cultural system of Confucianism, Buddhism and Taoism are all the basic tenets that should be complied with and practicing. In the complex of "skills" and "methods", the things waked up by martial arts are conscious of national quality, the self-identity of national culture, and the roots and soul of national stem. Therefore, the education of Martial Arts is not only a skill imparting, but also the educational process of national culture, traditional moral, and national spirit. Under these circumstances, it is self-evident of the role and significance in connection with the overseas publicity of martial arts.

\section{Advantages of Function}

Function is the weight in terms of measuring value. The reason why martial arts are pursued and admired by people is determined by its own value. The functions of Martial arts are polynary. The core parts of it are defending oneself and body-building.

Because of this feature, there are lively models appear from generation to generation. They really affect the desire and pursuit of people all over the world. And then enlighten people to learn the experiences and understanding the effect. Therefore, the

value of martial arts is achieved through practices. There will be no vivid understanding if there is no tempering process. The various forms are the outstanding advantages of martial arts in terms of manifestation. Be known as a traditional national sport, martial arts own various means to make people keep healthy. Martial arts including set pattern and sanda; training by themselves and with each other; there are a variety of manly art and weaponry; there are standing qigong and Xing gong; there are also static power and dynamic power; and there are well preserved breathing exercise and stunts. The various kinds of martial arts with provide a theoretical evidence for extensive knowledge and profound scholarship of it and a wide space for entertainment appreciation. 


\title{
The Basic Thinking of Export Popularization of Chinese Martial Arts
}

\author{
It should be made as an act of state for the Export Popularization of Chinese Martial Arts.
}

First, as a cultural project, the export popularization of Chinese Martial Arts should establish the institutions and organizations. There will be no success if there is no organization. Martial Arts is a cultural brand which owns abundant in content, obvious advantages and strong influence. It is a compound construction for the export popularization of Chinese Martial Arts. In the past, its development and growth was supported by the state sports functionaries (National Sports Commission which is the State Physical Culture Administration now). Second, maintaining by the inertia force of civilian tradition propulsion. The purposes of development are nationwide fitness and project expanding. From today's view of globalization trend, Chinese Martial Arts which have not only ethnic and cultural style, but also the characteristics of national technology. It is not enough to export popularization of Chinese Martial Arts only with the power of State Physical Culture Administration. In terms of the external promotion of national martial arts and national treasure, the level should be the nation grade. The units responsible for promoting the mission should be more than one. Therefore, we suggest that the external promotion of martial arts should be operation united by at least several units with national: Lead by the State Physical Culture Administration, coordinate with Ministry of Education, the Ministry of Culture, Ministry of Finance, and the National Tourism Administration. With regard to the development of Chinese culture and education, these state organs have their own main goals and channels of development. However, in the actual operation, there are interweaved parts and contradictions between them. The export popularization of Chinese Martial Arts, if co-ordinate with each other, this will be a national cultural strategic behavior with an unanimous purpose, sharing of resources, and a good effect.

The development of exporting popularization of Chinese Martial Arts requires establishing professional talent banks.

The professional and subjects' development require familiar with the inner and external environmental conditions. Filtering the professional resources and mastering professional population are the basic work of professional development. Since the foundation of new China, although we did a nationwide excavation and arrangements work of Martial Arts in the 1980s. However, because of the economic condition was limited, this kind of work was not intensive. So far, after nearly 30 years, how many schools of Martial Arts exist in China, how many civilian boxers and master-level figures that are worthy of protection, and how many diaphysis inheritance people of different schools; How many experts and professors, how many people are practicing martial arts, what kinds of martial arts are they practicing, and what are their degree of awareness martial arts, etc. I am afraid none of us can say clearly about them. It is a problem should be paid close attention to and to implement for the state functions and the majority of martial arts operators.

\section{Conclusion}

The great era calls for great cause and actions. The external promotion of martial arts requires the strategic thought and specific programs of global value chains. Along with the great rejuvenate the Chinese nation, China's international status is on the move. The national treasure---Martial Arts, should make full use of its good tradition to serve our national policy and nation; and make profits for Chinese nation's international status.

With regard to the outstanding martial arts culture, there is not only a need to protect, heritage, and develop it, but also to face it with an attitude of opening, blending, inclusive, and promoting. "The value of culture is not only just rest with how much GDP driven by it, but also rest with how much contribution made by culture itself in connection with constructing national core value system and taking up the historic mission of the national spirit." The increasingly prosperous of China is the good opportunity for the development of martial arts; and the required of China is the maximum value of the functions of martial arts.

The tide is flowing as boundless as the sea and sky, and it is the right time to set sail. In order to meet the various challenges in the process of external development of martial arts, and welcome the splendid spring of martial arts, there is a need to seize the opportune moment, and be filled with boundless pride with wise wisdom, steady conviction, and substantial pace. 


\section{References}

[1] Lin Yifu, Liu Mingxing. Economic Development Strategy and the Industrialization of China [J]. Economic Research 2004,7,48-58.

[2] Wu Shaozu. "History of Chinese Martial Arts", [M] Preface. People's Sports Press 1997,9,2

[3] Li Shengfu. "Medical Secrets of Shaolin Quan", [M]. People's Sports Press 2007,12,50 